\title{
MEHR GELD FÜR ZAHNTECHNIKER
}

Gehaltsanpassung-- Der Verband Deutscher ZahntechnikerInnungen vermeldet für das Jahr 2016 eine Erhöhung der Gehälter im Zahntechniker-Handwerk. Der Verdienst der Zahntechniker stieg somit um knapp 2,7 Prozent. Im Durchschnitt verdient ein Zahntechniker 2.350 Euro brutto, das sind mehr als 28 Prozent weniger im Vergleich zum durchschnittlichen Bruttoverdienst anderer Handwerker und knapp 58 weniger als alle Vollzeitbeschäftigten (3.708 Euro im Jahr 2016).

RED

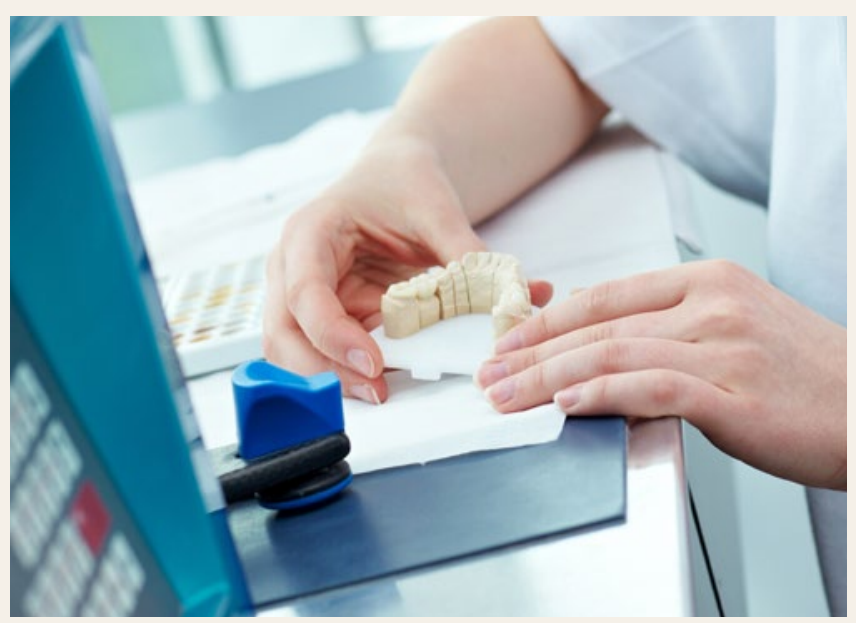

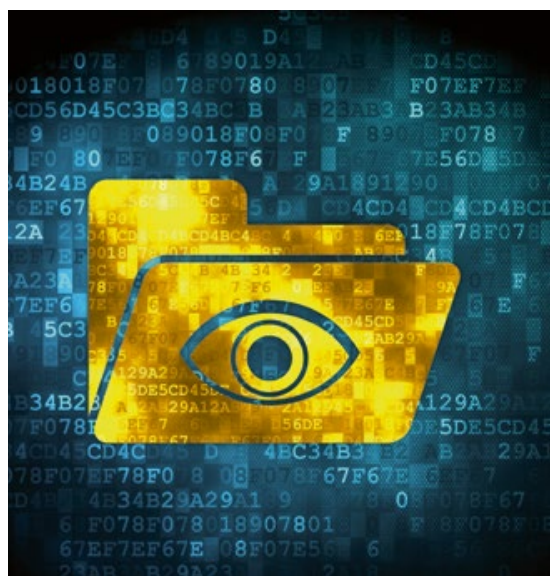

KZBV POSITIONIERT $\mathrm{SICH}$

Digitalisierung im Gesundheitswesen-- Die Vertreterversammlung (VV) der Kassenzahnärztlichen Bundesvereinigung (KZBV) hat sich Anfang November in Frankfurt/Main zur Digitalisierung im Gesundheitswesen positioniert und dazu mehrere Beschlüsse verabschiedet. Das 10-Punkte-Papier „Chancen nutzen, Datenschutz und Datensicherheit“ betont den Gestaltungswillen der Selbstverwaltung für eine Digitalisierungsstrategie. Digitale Anwendungen sollen Zahnärzten genügend Zeit für die Patientenversorgung lassen und bei der
Bewältigung der Bürokratielast helfen. Entstehende Kosten und der Einsatz (beispielsweise bei der Patientenberatung) müssten vollständig übernommen und honoriert werden. Überdies forderten die Mitglieder der VV den Gesetzgeber auf, die bis zum 31. Dezember 2018 verlängerte Frist für die Umsetzung des Versichertenstammdatenmanagements noch einmal zu verlängern und Sanktionen für Zahnärzte, Ärzte sowie Selbstverwaltung zu unterlassen.

MEHR ZUM THEMA AUF SEITE 32.

RED

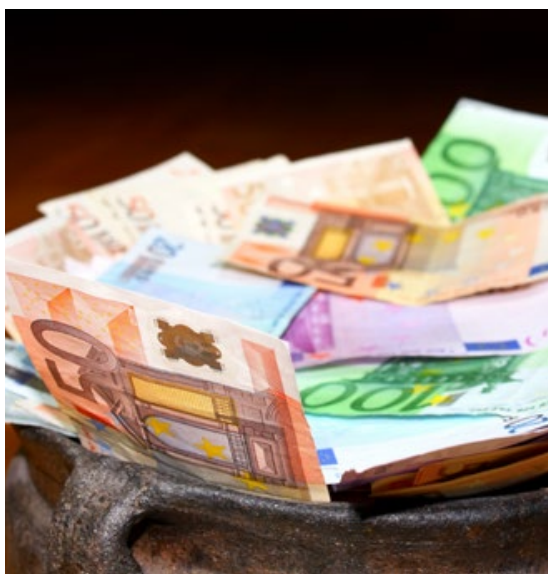

KASSEN BEEINFLUSSEN ÄRZTE WEITERHIN

\section{Manipulation von Diagnosen-- Die Kran-} kenkassen nehmen weiterhin Einfluss auf die Kodierung der Diagnosen ihrer Versicherten. Dies ist das Ergebnis einer Umfrage der Techniker Krankenkasse (TK).

Auf Basis der Diagnosen erhalten die Krankenkassen Mittel aus dem Gesundheitsfonds. Der Gesetzgeber hatte die Beeinflussung durch die Krankenkassen zwar im April 2017 verboten. Allerdings sind seit dem Inkrafttreten bereits wieder etwa 20 Prozent der befragten 1.000 Ärzte von Krankenkassen zu ihrer Diagnosestellung beraten worden, insgesamt rund 11.000 niedergelassene Ärzte. Die Untersuchung kommt zu dem Ergebnis, dass eine systematische Einflussnahme auf die ärztlichen Kodierungen weiterhin vorhanden ist und dass das Gesetz somit seine Wirkung verfehlt. Auch ein Sondergutachten des Wissenschaftlichen Beirats des Bundesversicherungsamtes kommt zu dem Schluss, dass es weiterhin Manipulationen gibt.

RED 